\title{
KONDISI PARIWISATA BERKELANJUTAN DI BIDANG SOSIAL BUDAYA BERDASAR PENGALAMAN DAN HARAPAN PENGUNJUNG DI PANTAI TANJUNG PAPUMA, JEMBER
}

\author{
Maria Pia Adiati; Anwar Basalamah \\ Hotel Management Department, Faculty of Economic and Communication, BINUS University \\ Jln. K.H. Syahdan No. 9, Palmerah, Jakarta Barat 11480, \\ mia_pia_adiati@hotmail.com; basalamah.a@gmail.com
}

\begin{abstract}
Jember becomes famous since the event of Jember Fashion Carnaval (JFC) which has been started since 2003. Along with the success of the JFC, Jember takes this moment to introduce the region as an attractive tourist destination in addition to JFC. Papuma beach is now a tourist icon of Jember. This beach offers a unique natural beauty as a combination of beach and forest. In the development of sustainable tourism, there are three pillars to note and they are environmental, economic and social. The purpose of this study is to determine the opinion of visitors to the state tourism Papuma Beach. This study uses descriptive qualitative approach by taking a more specific social dimension as an indicator, that is visitor satisfaction. In this study, beachgoers are asked to describe their experiences in Papuma Beach, by asking them some indicators, such as the existence of public transport, attraction, amenities, access, ancillary services, and experiences.
\end{abstract}

Keyword: destination, sustainability

\begin{abstract}
ABSTRAK
Jember mulai dikenal sejak adanya Jember Fashion Carnaval (JFC) yang sudah dimulai sejak tahun 2003. Seiring dengan kesuksesan event JFC, Jember mengambil momentum ini untuk memperkenalkan wilayahnya sebagai destinasi wisata yang menarik selain event JFC. Adalah Pantai Papuma yang sekarang menjadi ikon wisata Jember. Pantai ini menawarkan keindahan alam yang unik karena merupakan gabungan dari pantai dan hutan. Dalam pengembangan pariwisata berkelanjutan, ada tiga pilar yang perlu diperhatikan yaitu kondisi lingkungan, ekonomi dan sosial. Tujuan penelitian ini adalah untuk mengetahui pendapat pengunjung terhadap kondisi pariwisata di Pantai Papuma. Penelitian ini menggunakan metode deskriptif melalui pendekatan kualitatif dengan mengambil suatu dimensi sosial yang lebih spesifik sebagai indikator yaitu kepuasan pengunjung. Dalam penelitian ini, pengunjung pantai diminta menceritakan pengalaman mereka di Pantai Papuma, dengan menanyakan kepada mereka beberapa indikator, seperti existence of public transport, attraction, amenities, access, ancillary service, dan experiences.
\end{abstract}

Kata kunci: tujuan, berkelanjutan 


\section{PENDAHULUAN}

Menurut halaman portal Kementerian Pariwisata dan Ekonomi Kreatif, selama periode 20072011, industri pariwisata merupakan penyumbang devisa negara yang selalu masuk dalam peringkat lima besar. Jika dibandingkan dengan penyumbang devisa negara yang lain, maka industri pariwisata ini merupakan industri yang unik karena di dalamnya terdapat banyak komponen industri yang mendukungnya. Menurut Undang-Undang No 10 Tahun 2009 tentang Kepariwisataan, komponen yang masuk dalam industri adalah: (1) Usaha jasa pariwisata, yang mencakup jasa biro perjalanan wisata; jasa agen perjalanan wisata; jasa pramuwisata; jasa konvensi, perjalanan insentif dan pameran; jasa impresariat; jasa konsultan pariwisata; jasa informasi pariwisata. (2) Pengusahaan obyek dan daya tarik wisata, yang mencakup pengusahaan obyek dan daya tarik wisata alam; pengusahaan obyek dan daya tarik wisata budaya; pengusahaan obyek dan daya tarik wisata minat khusus. (3) Usaha sarana pariwisata, yang mencakup penyediaan akomodasi; penyediaan makanan dan minuman; penyediaan angkutan wisata; penyediaan sarana wisata tirta; kawasan pariwisata.

Salah satu kekayaan yang dimiliki Indonesia dalam menopang industri pariwisata adalah kekayaan alam yang beragam. Indonesia memiliki wisata laut, gunung, hutan dan danau. Salah satu daerah yang mengandalkan kekayaan alam sebagai penghasil devisa daerah adalah Kabupaten Jember. Kabupaten Jember mempunyai beberapa wisata alam seperti Pantai Puger, Pantai Papuma, Pantai Watu Ulo. Adalah Pantai Papuma yang sekarang menjadi ikon wisata Jember. Pantai ini menawarkan keindahan alam yang unik karena merupakan gabungan dari pantai dan hutan sehingga Pantai Papuma adalah pilihan wisata utama di Jember. Pantai Papuma ramai sekali dikunjungi baik penduduk Jember maupun penduduk di luar Jember sehingga keadaan pantai ramai sekali di waktu libur.

Kondisi yang ramai di Pantai Papuma mempunyai keuntungan tetapi juga kerugian. Keuntungannya tentu dari sisi bisnis yaitu untuk pengelola, tetapi dari segi lingkungan, tentu hal ini perlu dipertimbangkan juga agar keindahan Pantai Papuma tidak rusak sehingga tetap mampu menjadi daya tarik wisata berbasis alam. Saat ini muncul suatu kesadaran bahwa pengelolaan pariwisata juga mampu menjadikan objek tersebut mampu berlanjut (sustain) di masa mendatang dengan tetap memperhatikan kepentingan semua pihak pemangku kepentingan (stakeholder).

Perumusan masalah dalam penelitian ini adalah untuk mengetahui kondisi pariwisata berkelanjutan pada satu dimensi sosial budaya dalam hal ini adalah mengetahui harapan dan pengalaman setelah berkunjung ke Pantai Papuma.

Tujuan dari penelitian ini adalah untuk mengetahui bagaimana harapan dan pengalaman dari pengunjung agar bisa digunakan sebagai acuan untuk peningkatan pengelolaan wisata di Pantai Papuma. Unit yang di pilih adalah pengunjung karena pengunjung adalah penikmat langsung dan yang memberikan manfaat ekonomi bagi pengelola dan komunitas yang terlibat dalam pengelolaannya. Selain itu tingkat kedatangan pengunjung merupakan hal yang menentukan apakah suatu destinasi wisata itu layak dan bagus dikunjungi atau tidak.

\section{Pengertian Destinasi}

WTO (World Tourism Organization) mengartikan definisi destinasi sebagai "Part of destination. A homogeneous tourism region or a group of local govenment administrative regions" (Ricardson dan Fluker, 2004:48).

Region yang dimaksudkan adalah (1) kelompok negara-negara dalam area geografis; (2) sebuah kawasan dalam suatu negara, biasanya kawasan destinasi wisata (Ricardson dan Fluker, 2004). 
Menurut Carter dan Fabricius (Dalam Dávid, 2009) menyatakan:

"Destination is a physical location where the tourist is spending at least one night. It is containing tourist attractions, products, relating services that are necessary to meet the stay of a tourist on the place at least for one day. Destination has physical and administrative limits, which are determining its management, and has an image and perception. It includes a lot of elements being concerned, it is capable for constructing a network, a cooperation and to become a bigger destination; the determination of destination is made from the point of view of the tourist".

Selama ini, definisi destinasi sering disamakan dengan objek daerah tujuan wisata (ODTW), tetapi saat ini definisi yang sering digunakan adalah destinasi dibanding ODTW. Destinasi secara umum diartikan sebagai area atau lokasi yang mempunyai atraksi wisata yang dilengkapi dengan berbagai fasilitas dan pelayanan yang menunjang untuk memenuhi kebutuhan pengunjung atau tamu.

\section{Komponen-komponen destinasi}

Inskeep (1991) menyatakan bahwa komponen-komponen dalam pengembangan destinasi wisata terdiri dari Tourist attraction and activities, accommodation, other tourist facilities and services, transportation facilities and services, other infrastructure, dan institutional element.

Komponen-komponen pariwisata mendukung dalam pengembangan destinasi wisata, yang dapat memberikan ciri khas atau karakteristik destinasi tersebut. Hadinoto (1996) menyebutkan bahwa komponen destinasi wisata terdiri dari: (1) Atraksi di destinasi, adalah atraksi yang ditampilkan di daerah tujuan wisata dan citra yang dihasilkan atau diciptakan bagi wisatawan. (2) Fasilitas di destinasi, antara lain akomodasi, makan, minum, hiburan dan rekreasi. (3) Aksesibilitas, yaitu kemudahan-kemudahan yang dinikmati di daerah tujuan wisata.

Sementara itu menurut Cooper (1998), komponen destinasi meliputi: Attraction, amenities, Access and Ancillary services. Atraksi (attraction) adalah bentuk kegiatan budaya, keindahan alam dan event yang memotivasi wisatawan untuk datang berkunjung. Amenities meliputi fasilitas dan pelayanan yang disediakan untuk wisatawan di destinasi wisata seperti penyediaan akomodasi, makan dan minum, hiburan dan pelayanan lainnya. Sedangkan aksesibilitas (access) adalah penyediaan sarana transportasi dengan berbagai jenis baik darat, laut maupun udara sesuai dengan kebutuhan wisatawan dan prasarana jalan raya yang memberikan kemudahan untuk mencapai destinasi wisata. Yang terakhir adalah ancillary services atau pelayanan tambahan yang meliputi pelayanan baik untuk wisatawan maupun penyedia jasa pariwisata melalui lembaga/dinas pariwisata lokal.

\section{Definisi Pariwisata Berkelanjutan}

Keberhasilan suatu destinasi wisata untuk tetap menarik dikunjungi merupakan suatu usaha yang tidak mudah karena banyak faktor bisa membuat suatu destinasi tidak lagi menarik turis. Faktorfaktor tersebut antara lain kerusakan lingkungan, atraksi yang ditampilkan tidak ada perubahan (monoton), maupun masyarakat setempat yang tidak mendukung usaha pariwisata. Jika pada akhirnya suatu destinasi tidak lagi menarik pengunjung atau sepi dikunjungi oleh wisatawan, maka usaha pariwisata di destinasi tersebut akan terhenti dan merugikan banyak pihak.

Pendapat mengenai sustainability tourism disampaikan oleh Eber (1992):

"Sustainability tourism is tourism and associated infrastructure that: both now and in the future operate within natural capacities for the regeneration and future productivity of natural resources; recognize the contribution that people and communities, customs and lifestyles, make to the tourism experience; accept that these people must have an equitable share in the economic benefits of local people and communities in the host area". 
Hunter (dalam Ritchie dan Crouch, 2003) menyampaikan pendapatnya mengenai pembangunan pariwisata berkelanjutan:

"The current paradigm of sustainable tourism development is based on the principles that this kind of development should: (1) meet the needs and wants of the local host community in terms of improved living standards and quality of life; (2) satisfy the demands of tourists and the tourism industri and continue to attract them in order to meet the first aim; and (3) safeguard the environmental resource base for tourism, encompassing natural, built and cultural components, in order to achieve both of the preceding aims.

Kondisi yang menggambarkan suatu destinasi yang bisa bertahan hingga nanti diungkapkan oleh Wray (dalam Damanik dan Teguh, 2012):

\begin{abstract}
"Setiap destinasi dapat berkembang secara berlanjut jika langkah-langkah berikut dilakukan dengan cermat. Pertama, melindungi dan meningkatkan daya tarik alam dan buatan yang menjadi basis industri pariwisata. Kedua, menggunakan setiap sumberdaya yang tersedia sesuai dengan nilai dan aspirasi masyarakat lokal masa kini dan yang akan datang, serta menghasilkan kontribusi nyata bagi kesejahteraan mereka. Ketiga, mengembangkan dan memasarkan produk dengan tepat dengan memperhatikan perbedaan dan daya saingnya, sehingga tetap mampu secara fleksibel merespon perubahan pasar. Keempat, meningkatkan kontribusi pariwisata terhadap kemajuan ekonomi di destinasi dan melakukan promosi berkelanjutan. Kelima, meningkatkan daya tarik destinasi, menjamin kesesuaian promosi dengan fakta destinasi, mendorong pertambahan kunjungan-ulang dan meningkatkan reputasi destinasi."
\end{abstract}

Melalui pendapat yang disampaikan Wray (dalam Damanik dan Teguh, 2012), menggambarkan bahwa kondisi yang berkembang secara berlanjut dapat dicapai jika memperhatikan beberapa aspek. Aspek-aspek tersebut adalah melindungi dan meningkatkan daya tarik, menggunakan sumber daya secara maksimal baik pada masa kini dan masa yang akan datang dengan memperhatikan nilai masyarakat lokal, lalu mengembangkan produk yang ada dan dipasarkan dengan tepat, serta memberikan manfaat secara ekonomi bagi masyarakat sekitar destinasi, dan yang terakhir serta penting adalah menjamin bahwa promosi yang dilakukan harus dilakukan sesuai dengan fakta yang ada, sehingga menimbulkan pertambahan kunjungan-ulang dan meningkatkan reputasi destinasi.

\title{
Dimensi Pariwisata Berkelanjutan
}

Dalam menciptakan pariwisata yang berkelanjutan, ada beberapa dimensi yang berhubungan. Menurut UNWTO (2004), dimensi pariwisata yang merupakan indikator suatu destinasi dianggap berlanjutan yaitu:

"Sustainability principles refer to the environmental, economic and sociocultural aspects of tourism development, and a suitable balance must be established between these three dimensions to guarantee its long-term sustainability. Thus, sustainable tourism should: (1) Make optimal use of environmental resources that constitute a key element in tourism development, maintaining essential ecological processes and helping to conserve natural heritage and biodiversity. (2) Respect the socio-cultural authenticity of host communities, conserve their built and livingcultural heritage and traditional values, and contribute to intercultural understanding and tolerance. (3) Ensure viable, long-term economic operations, providing socio-economic benefits to all stakeholders that are fairly distributed, including stable employment and income-earning opportunities and social services to host communities, and contributing to poverty alleviation.

Sustainable tourism development requires the informed participation of all relevant stakeholders, as well as strong political leadership to ensure wide participation and consensus building. Achieving sustainable tourism is a continuous process and it requires constant monitoring of impacts, introducing the necessary preventive and/or corrective measures 
whenever necessary. Sustainable tourism should also maintain a high level of tourist satisfaction and ensure a meaningful experience to the tourists, raising their awareness about sustainability issues and promoting sustainable tourism practices amongst them."

Untuk bisa tetap bertahan dalam pengembangan suatu destinasi wisata (sustain), ada banyak aspek atau dimensi yang harus dipertimbangkan, dan menurut UNWTO, dimensi tersebut adalah lingkungan, sosial-budaya dan ekonomi.

\section{METODE}

Penelitian ini adalah penelitian deskriptif dengan pendekatan kualitatif dimana tujuan dari penelitian ini untuk menjawab pertanyaan dan untuk mencari tahu bagaimana kondisi pariwisata berkelanjutan di Pantai Papuma, Jember dalam dimensi sosial menurut para pengunjungnya.

Pendekatan yang dilakukan adalah menetapkan indikator yang menunjukkan kondisi pariwisata berkelanjutan, mengumpulkan bukti lalu mendeskripsikan hasil penelitian dan membandingkan kondisinya dengan indikator.

Variabel yang dipakai dalam penelitian ini terdiri dari Variabel X dan Variabel Y, dimana variabel $\mathrm{X}$ adalah variabel dari dimensi pariwisata berkelanjutan dalam bidang sosial-budaya (UNWTO, 2004) dan variabel Y yang merupakan kondisi yang menggambarkan pariwisata berkelanjutan di suatu destinasi (Hunter,1997). Sub-variabel dan indikator digunakan untuk menunjukkan pengukuran dari variabel $\mathrm{X}$. Sub variabel yang digunakan adalah visitor fulfillment (Presenza et al, 2005; UNWTO, 2004; Cooper, 1998).

Definisi operasional variabel adalah sebagai berikut: (1) Dimensi Socio-cultural. Dimensi sosial budaya dalam usaha pembangunan pariwisata berkelanjutan berarti harus menghormati keaslian budaya sosial dari masyarakat setempat. Melestarikan warisan budaya dan nilai-nilai tradisional sehingga tidak terjadi pergeseran budaya karena perkembangan pariwisata dan kebutuhan pengunjung terpenuhi. (2) Sustainable tourism development. Pembangunan suatu usaha pariwisata yang berkelanjutan berarti kondisi usaha wisata tersebut dapat memenuhi keinginan dan kebutuhan masyarakat sekitar, memuaskan pengunjung yang datang dan pengelola. Pengelola dan pengunjung yang terpuaskan akan menarik turis untuk datang serta selalu menjaga lingkungan alam dan budaya.

Penarikan sampel yang dilakukan dalam penelitian ini menggunakan nonprobability sampling dengan teknik purposive/judgement sampling. Penggunaan sampel seperti ini bisa mendapatkan kondisi yang paling mendekati dalam pembangunan pariwisata yang berlanjut di Pantai Papuma, Jember. Purposive sample adalah strategi penarikan sampel yang paling umum dalam penelitian sosial karena:

" In purposive sampling, you decide the purpose you want informants (or communities) to serve, and you go out to find some. This is somewhat like quota sampling, except that there is no overall sampling design that tells you how many of each type of informant you need for a study. You take what you can get” (Bernard, 2006:189).

Keunikan dari penelitian kualitatif yang menggunakan sampel ini adalah peneliti sebagai instrumen yang berpengaruh dalam penelitian., "This can involve developing a framework of the variables that might influence an individual's contribution and will be based on the researcher's practical knowledge of the research area, the available literature and evidence from the study itself" (Marshall, 1996) 
Jumlah pengunjung yang diwawancara sebanyak 24 orang. Pengunjung ditemui dalam rentang waktu satu minggu sehingga dapat mencatat pendapat dari pengunjung yang datang pada hari kerja dan pada akhir pekan. Teknik pengumpulan data primer menggunakan participant observation dan indepth semi structure interiew. Data sekunder diperoleh dengan cara tidak langsung yaitu melalui literatur, dokumen, data pengunjung, jurnal penelitian ilmiah, tesis penelitian sebelumnya dan dari situs internet.

\section{HASIL DAN PEMBAHASAN}

Pantai Tanjung Papuma terletak di sebelah selatan Kota Jember, salah satu kota di Provinsi Jawa Timur yang berada di jalur Bromo, Ijen, dan Bali. Pantai pasir putih ini terletak kurang lebih 37 km ke arah selatan dari Kota Jember, atau kurang lebih 235 km dari Kota Surabaya. Pantai ini secara geografis terletak di Desa Lojejer, Kecamatan Wuluhan, Kabupaten Jember. Pantai Papuma tergolong unik karena bersebelahan persis dengan Pantai Watu Ulo. Pantai Watu Ulo secara geografis terletak di Desa Sumberejo, Kecamatan Ambulu. Pantai Watu Ulo dan Pantai Papuma mempunyai karakteristik yang berbeda. Walaupun secara geografis persis bersebelahan, pengelola dari dua tempat ini berbeda. Pantai Watu Ulo dikelola oleh Pemerintah Daerah dan Pantai Tanjung Papuma dikelola oleh Perum Perhutani Unit II-Jawa Timur. Pantai Papuma merupakan ikon destinasi wisata di Jember karena Pantai ini sangat diminati dan sangat ramai dikunjungi. Bahkan Kantor Dinas Pariwisata dan kebudayaan Jember juga merekomendasikan Pantai Papuma sebagai destinasi wisata unggulan di Jember.

Pantai Papuma diminati karena sangat unik. Untuk mencapai Pantai Papuma harus melewati dulu area hutan produksi dan saat tiba di area pantai, pengunjung dimanjakan oleh keindahan alam lautnya yang beragam karena ada pasir putih dan pasir yang berwarna perak. Pantai ini terasa sejuk karena bersebelahan dengan hutan lindung. Ramainya pantai ini terutama saat musim libur dan peak season terjadi saat Idul Fitri dan Tahun Baru. Di Pantai Papuma, pengelola menyediakan juga fasilitas akomodasi dan kegiatan outdoor yang dikelola oleh Perhutani serta warung-warung makan yang dikelola oleh mitra pengelola (yang merupakan penduduk setempat), serta dapat menyewa perahu nelayan untuk menikmati indahnya laut Papuma.

Di bawah ini adalah tabel jumlah wisatawan pada tahun 2011-2013, dimana tahun 2013 data yang diambil hingga bulan Juli 2013.

Tabel 1 Kunjungan wisatawan per bulan

\begin{tabular}{cccc}
\hline \multirow{2}{*}{ Bulan } & $\mathbf{2 0 1 1}$ & $\mathbf{2 0 1 2}$ & $\mathbf{2 0 1 3}$ \\
\cline { 2 - 4 } & Pengunjung & Pengunjung & Pengunjung \\
\hline Jan & 16100 & 22595 & 17077 \\
Feb & 11975 & 11492 & 8296 \\
Mar & 10387 & 34087 & 18195 \\
Apr & 10939 & 15985 & 14088 \\
Mei & 14756 & 17019 & 21995 \\
Jun & 20509 & 18967 & 22800 \\
Juli & 16630 & 17067 & 11651 \\
Ags & 7113 & 50657 & 0 \\
Sept & 53269 & 23844 & 0 \\
Okt & 12695 & 22701 & 0 \\
Nov & 13972 & 19262 & 0 \\
Des & 25308 & 32991 & 0 \\
\hline Total & $\mathbf{2 1 3 6 5 3}$ & $\mathbf{2 6 4 0 7 2}$ & $\mathbf{9 7 0 2 5}$ \\
\hline
\end{tabular}




\section{Pembahasan Sub Variabel dan indikatornya.}

Tujuan dari sub variabel ini adalah,” To provide a safe, satisfying and fulfilling experience for visitors, available to all without discrimination by gender, race, and disability or in other ways" (UNWTO, 2004).

Indikator dan Pembahasannya: (1) Existence of public transport suitable for mobility of persons with disabilities. Menurut pengamatan dan pendapat dari pengunjung, belum ada transportasi publik dan jalur pengunjung di Pantai Papuma yang mendukung kaum difabel untuk berwisata ke Pantai Papuma sehingga membuat Pantai Papuma tidak bisa dikunjungi kaum difabel tanpa bantuan dari orang lain. (2) Level of satisfaction by visitors. Hasil wawancara dengan pengunjung menggunakan indikator dari berbagai teori, dengan hasil sebagai berikut:

Tabel 2 Tabel Ringkasan Hasil Wawancara

\begin{tabular}{|c|c|c|}
\hline NO & KOMPONEN & HASIL \\
\hline 1 & PENGALAMAN DALAM HAL & \\
\hline & $\begin{array}{l}\text { - Suatu pengalaman yang baru setelah } \\
\text { Berkunjung }\end{array}$ & $\begin{array}{l}\text { Empat belas orang dari empat belas orang menjawab } \\
\text { mereka mendapat pengalaman yang beragam setelah } \\
\text { berkunjung ke Papuma. }\end{array}$ \\
\hline & - Kekayaan kebudayaan lokal & $\begin{array}{l}\text { Empat belas orang dari empat belas orang menjawab } \\
\text { tidak pernah melihat acara kebudayaan lokal saat } \\
\text { mereka mengunjungi Papuma. }\end{array}$ \\
\hline & - Kebisingan kendaraan & $\begin{array}{l}\text { Empat belas orang dari empat belas orang mengatakan } \\
\text { tidak merasa terganggu dengan kebisingan kendaraan } \\
\text { yang melintas. Selain itu parkir letaknya cukup jauh dari } \\
\text { pantai sehingga tidak mengganggu kenyamanan mereka } \\
\text { saat menikmati pantai. }\end{array}$ \\
\hline & - Kebersihan & $\begin{array}{l}\text { Empat belas orang dari empat belas orang menjawab } \\
\text { tidak bersih walaupun dari segi kenyamanan ada } 1 \text { orang } \\
\text { yang masih bisa menerima kondisi seperti ini. Ke tiga } \\
\text { belas yang lain kurang suka dengan keadaan kotor } \\
\text { seperti ini }\end{array}$ \\
\hline & $\begin{array}{l}\text { - Harga tiket masuk dibanding dengan } \\
\text { pengalaman yang didapatkan dan fasilitas } \\
\text { umum yang disediakan. }\end{array}$ & $\begin{array}{l}\text { - Jika dibandingkan dengan pengalaman yang mereka } \\
\text { dapatkan setelah berwisata ke Papuma, hanya } 1 \\
\text { orang yang menyatakan bahwa pengalamannya } \\
\text { kurang sebanding dengan tiket mauk yang } \\
\text { dibayarkan. Sementara } 13 \text { orang lainnya } \\
\text { menyatakan sebanding antara pengalaman dengan } \\
\text { harga tiket. Alasannyanya sebanding adalah dengan } \\
\text { harga tiket sebesar itu tetapi mendapat keindahan } \\
\text { alam yang luar biasa. } \\
\text { Jika dibandingkan antara tiket masuk dengan } \\
\text { fasilitas umum yang tersedia, jawabannya berbeda } \\
\text { yaitu } 12 \text { orang menjawab kurang sebanding, } \\
\text { sementara hanya } 2 \text { orang yang menyatakan } \\
\text { sebanding. Fasilitas umum yang paling dikeluhkan } \\
\text { yaitu toilet umum yang kurang bagus, dan terkesan } \\
\text { tidak terawat }\end{array}$ \\
\hline & - Kepadatan lahan & $\begin{array}{l}\text { Dari empat belas wisatawan yang diwawancara, } 13 \\
\text { orang mengatakan tidak merasakan kepadatan } \\
\text { pengunjungnya. Tetapi ada lima orang yang mengatakan } \\
\text { bahwa Papuma akan ramai pada saat liburan saja } \\
\text { terutama hari besar dan Lebaran sertaa tahun baru. } \\
\text { Walaupun wawancara juga dilakukan pada akhir }\end{array}$ \\
\hline
\end{tabular}


pekan,tetapi menurut persepsi wisatawan kondisi ini masih bisa ditolerir. Ada satu orang yang menyatakan bahwa Papuma padat di hari dilakukan wawancara karena bertepatan dengan akhir pekan. Sehingga bagi wisatawan ini, kondisi ini kurang menyenangkan karena susah untuk mencari tempat duduk bagi keluarga besarnya.

\section{AKSESIBILITAS}

- Kondisi jalan masuk

- Penunjuk jalan ke arah Papuma

- Jalur untuk penderita cacat di Papuma
5 orang menyatakan tidak mudah jalan masuk ke Papuma karena kondisinya yang kurang mulus walaupun sudah jalan aspal, catatan dari wisatawan ini adalah, di beberapa titik yang tidak mulus terdapat di tanjakan dimana hal ini dapat membahayakan keselamatan serta tidak semua kendaraan dengan mudah mencapai Papuma seperti bis besar. Selain itu kondisi jalan yang sempit juga dipertimbangkan untuk ke depannya.

Untuk penunjuk jalan memang relatif dilihat dari mana arah datangnya wisatawan tersebut. Tetapi ada dua arah yang menjadi patokan penting yaitu:

- Dari arah Surabaya ke Ambulu

Untuk dari arah Surabaya memang terdapat ramburambu yang menunjukkan arah ke Papuma, tetapi memang tidak terlalu menarik perhatian.

- Dari arah Jember kota / Banyuwangi ke Ambulu. Untuk dari arah Jember kota / Banyuwangi, belum terlihat adanya rambu-rambu penunjuk arah ke Papuma sehingga wisatawan dari arah Bali dan Banyuwangi mungkin tidak mengetahui adanya Pantai Papuma.

2 orang wisatawan menyatakan tidak tahu apakah banyak petunjuk jalan atau tidak karena tidak memperhatikan (mereka ikut dalam rombongan sehingga tidak memperhatikan jalan).

Dan menurut observasi dari jika sudah ada di sepanjang jalan Ambulu menuju Papuma, terdapat banyak penunjuk jalan.

Semua turis menyatakan bahwa tidak adanya jalur untuk penderita cacat di kawasan wisata Papuma. Biasanya kondisi yang terjadi, para kaum difabel ini biasanya datang dengan keluarganya.

\section{ATRAKSI}

- Keunggulan / daya tarik Papuma

Semua wisatawan menunjukkan bahwa keunggulan Papuma adalah keindahan alamnya baik dari hutan jati, hutan lindung, pantai, batu karang dan lautnya, ombak di pantai maupun kekayaan biodiversiti laut yang kaya.

Dari 14 wisatawan hanya 4 yang mengatakan ada toko souvenir di Papuma, sementara yang lainnya tidak melihat atau tidak mengetahuinya. Hal ini menunjukkan kurang terlihatnya toko souvenir tersebut padahal toko souvenir merupakan poin penting dalam penyelenggaraan pariwisata yang dapat menciptakan pengalamaan yang utuh yang didapat wisatawan. Dari 4 orang yang melihat toko souvenir hanya satu yang memperhatikan jenis souvenirnya yaitu kaos bertuliskan Papuma dengan bahan yang biasa.

- Makanan Khas Papuma 
- Penginapan di Papuma

- Pelayanan dari staff dari Papuma

tampaknya tidak diketahui oleh wisatawan karena memang tidak ada. Tetapi makanan umum yang dijual dan ini diketahui oleh wisatawan adalah ikan bakar yang memang umum dijual di pantai serta mie rebus dan nasi goreng serta kelapa muda. Untuk kualitas, rasanya cukup bisa dinikmati.

2 orang menjawab cukup memadai bila dilihat dari sisi fisik dan fasilitas bangunannya saja walaupun belum pernah menginap. Alasan mengapa dibilang memadai adalah jika hanya untuk tinggal sementara di Papuma, cukup memadai karena orang datang ke Papuma untuk menikmati alam dan bukan untuk tinggal berlama-lama di kamar.

12 orang menjawab tidak tahu karena belum pernah menginap disana.

Untuk pelayanan staff 7orang menyatakan pelayanannya cukup ramah, 3 orang menyatakan tidak tahu dan 2 orang menyatakan tidak ramah. Catatan untuk pelayanan dari staff: perlu dilatih lagi agar bisa melayani lebih baik.

$\begin{array}{ll}5 & \text { TATA RUANG } \\ & \text { - Penataan ruang di Papuma }\end{array}$

- Kenyamanan dengan tata ruang

- Akses untuk menuju Gua Jepang
2 orang mengatakan rapi, 3 orang mengatakan cukup rapi tetapi masih perlu penataan yang lebih baik dan sisanya mengatakan kurang rapi. Alasan dari penataan yang kurang rapi adalah antara warung tidak tertata rapi, serta camping ground terlihat tersebar dimana-mana sehingga pemandangannya kurang bagus dan juga toilet yang ada tidak tersebar secara merata.

Hanya 1 orang yang menjawab nyaman dan 1 orang lagi yang cukup nyaman dengan tata ruang yang ada, sementara 12 orang menjawab tidak nyaman dengan tata ruang yang sekarang.

Semua wisatawan emgnatakan tidak mengetahui adanya Gua Jepang, sehingga mereka juga tidak mengetahui akses untuk ke Gua Jepang.

\section{KESAN}

- Jika ada wacana dibangun waterpark / Ada 3 orang yang setuju dengan catatan, bila hal itu kolam renang dapat meningkatkan daya tarik pengunjung dan terus dipelihara dengan baik.Jika tidak dipelihara,lebih baik tidak usah membuat kolam renangnya.

10 orang menjawab tidak setuju dan 1 orang menjawab sangat tidak setuju. Alasannya karena keunggulan Papuma adalah alamnya sehingga seharusnya lebih menguatkan potensi alamnya, bukan atraksi buatan karena di kota Jember sendiri sudah ada kolam renang buatan. Orang ke Papuma untuk mencari suasana alam, dan jika dibangun kolam renang, suasananya berubah seperti suasana kota.

- Rekomendasi ke orang lain 12 orang menjawab akan merekomendasikan Papuma ke orang lain karena alamnya yang indah sementara 2 orang lagi menjawab bahwa mereka belum berani merekomendasikan Papuma ke orang lain apa lagi ke turis asing bila kebersihan belum ditingkatkan.

- Akan mengunjungi lagi Papuma Semua wisatawan menjawab ya, mereka akan berkunjung lagi ke Papuma.

7 SARAN

- Saran untuk pengelola
Penerangan, kebersihan, penunjuk jalan diperbanyak, akses jalan, promosi, lahan parkir yang sistematis belum 
terlihat di pantai ini, sosialiasi dan promosi Papuma, toilet umum diperbanyak dan lebih bersih,, jalan masuk menuju loket di lebarkan, tambah tempat untuk membuang sampah serta buat peraturan tentang membuang sampah.bila perlu kenakan denda jika membuang sampah sembarangan, pengembangan ekowisata, wisata bahari, dan wisata pendidikan sehingga konsentrasi pengunjung bisa tersebar dan potensi wisata Papuma bisa optimal.

- Jenis wisata yang dikembangkan Menurut responden, jenis wisata yang cocok dikembangkan untuk Papuma adalah wisata bahari, ekowisata dan wisata pendidikan.

\section{SIMPULAN}

Simpulan dari hasil wawancara yang dilakukan menggambarkan bahwa pengunjung puas dan tidak puas pada beberapa hal. Gambaran kepuasan dan ketidakpuasan pengunjung, tergambar di tabel berikut.

Tabel 3 Tingkat Kepuasan dan Ketidakpuasan Pengunjung Berdasar Hasil Wawancara

\section{KONDISI POSITIF (PENGUNJUNG PUAS)}

- $\quad$ Pengunjung mendapat pengalaman yang beragam setelah mengunjungi Papuma.

- Pengunjung merasa tidak terganggu dengan kebisingan kendaraan di Papuma.

- Harga tiket tidak mahal dibandingkan pengalaman berwisata.

- $\quad$ Pengunjung merasa tidak terlalu padat (kecuali saat peak season).

- Jalan masuk papuma termasuk mudah dilewati tetapi perlu perbaikan di area yang berlubang.

- Daya tariknya merupakan kekuatan Papuma.

- $\quad$ Pelayanan dari staff sebagian besar sudah baik dan ramah tetapi perlu peningkatan pelatihan.

\section{KONDISI NEGATIF (PENGUNJUNG TIDAK PUAS)}

- Kebersihan yang kurang membuat pengunjung tidak nyaman.

- Fasilitas umum yang disediakan pengelola belum memadai dan kurang bersih.

- Penunjuk jalan belum banyak yang mengarahkan ke Papuma terutama di area kota Jember.

- Belum adanya transport publik dan jalur khusus untuk penyandang difabel.

- Toko suvenir walaupun tersedia tetapi tidak banyak yang tahu keberadaannya serta jenis suvenir yang ditawarkan terbatas.

- Tata ruang yang dirasa kurang rapi dan tidak nyaman dirasakan pengunjung.

- Gua Jepang walaupun dimasukkan ke dalam peta wisata tetapi banyak tidak diketahui lokasinya oleh pengunjung.

Selain memberikan pendapat dan pandangan pada pengelolaan Pantai Papuma, para pengunjung juga memberikan saran sebagai berikut: (1) Penerangan, kebersihan, penunjuk jalan diperbanyak, akses jalan masuk diperbaiki, promosi Papuma ditingkatkan, lahan parkir yang sistematis dibangun, toilet umum diperbanyak dan lebih bersih, jalan masuk menuju loket di lebarkan, tempat sampah untuk membuang sampah ditambah serta membuat peraturan tentang membuang sampah, bila perlu kenakan denda jika membuang sampah sembarangan, pengembangan ekowisata, wisata bahari, dan wisata pendidikan sehingga konsentrasi pengunjung bisa tersebar dan potensi wisata Papuma bisa optimal. (2) Jenis wisata yang cocok dikembangkan di Pantai Papuma adalah wisata bahari, ekowisata dan wisata pendidikan. Wisata bahari perlu dikembangkan karena sesuai dengan keunggulan Pantai Papuma yaitu laut sehingga akan meningkatkan pengetahuan tentang kekayaan laut di Papuma. 
Ekowisata perlu dikembangkan di Pantai Papuma karena selain pantai, ada hutan lindung yang juga menarik untuk program penyelamatan hutan dan pantai sambil berwisata. Wisata pendidikan juga perlu dikembangkan karena banyak jenis biota laut dan tumbuhan vegetasi pantai di hutan lindung yang bisa dipelajari untuk siswa maupun peneliti. Dalam kaitan dengan pengembangan pariwisata berkelanjutan dimana kondisi yang berlanjut (sustain) adalah kondisi yang bisa mengakomodir semua pemangku kepentingan, maka jawaban dari responden dan saran-saran yang disampaikan bisa menjadi pertimbangan dan masukkan bagi pengelola dalam pengelolaan dan penentuan kebijakan jangka panjang.

\section{DAFTAR PUSTAKA}

Bernard, R. H. (1995). Research Methods in Anthropology ( $2{ }^{\text {nd }}$ Edition). London: Sage Publications.

Crouch, G. I., Ritchie, JR Brent. (2003). The Competitiveness Destination: A Sustainable Tourism Perspective. CABI Publishing.

Damanik, J., \& Teguh, F. (2012). Manajemen Destinasi Pariwisata Sebuah Pengantar Ringkas. Kepel Press.

Inskeep, E. (1991). Tourism planning: an integrated and sustainable development approach. International Thompson Publishing Company.

L. Dávid. (2009). Destination Managament: Necessity And Tasks Of Tourism Destination Management in Hungary.

UNWTO. (2004). Indicators of Sustainable Development for Tourism Destinations-A Guide Book. Madrid. 